\title{
Assessment of the relationship between patellar volume and chondromalacia patellae using knee magnetic resonance imaging
}

\author{
(D) Mehmet Sirik, ${ }^{1}$ (D) Abuzer Uludag ${ }^{2}$ \\ ${ }^{1}$ Department of Radiology, Adiyaman University Faculty of Medicine, Adiyaman, Turkey \\ ${ }^{2}$ Department of Orthopedics and Traumatology, Adiyaman University Faculty of Medicine, Adiyaman, Turkey
}

\begin{abstract}
OBJECTIVE: In this study, we evaluated the relationship between patellar volume and chondromalacia patellae.

METHODS: A total of 162 patients who underwent knee magnetic resonance imaging (MR) due to knee pain at our department between January 2017 and May 2017 were included in this study. Of the cases, 111 were chondromalacia patellae, and 51 were healthy individuals. The patella volumes of all cases were analyzed using semi-automated software. Staging in cases with chondromalacia was graded according to the Outerbridge classification (stages 1-4). The relationship between patellar volume, presence of chondromalacia, cartilage thickness, age, and sex was analyzed statistically.

RESULTS: Of the 162 cases, 67 (41.4\%) were male, and 95 (58.6\%) were female. The median age of the cases was 44. Patellar volume was a minimum of 12.24 , a maximum of 39.44 , and a median $21.4 \mathrm{~cm}^{3}$, and it was higher in cases with chondromalacia $(p=0.026)$. In patients with chondromalacia patellae, the thickness of cartilage in the medial facet was lower. There was a statistically significant weak positive correlation between chondromalacia grade and patellar volume $(p=0.031, r=0.204)$.

CONCLUSION: This study showed that chondromalacia patellae, one of the important causes of chronic frontal knee pain, has a statistically significant relationship with patellar volume. The medial facial cartilage of the patella was thinner than in cases with chondromalacia patellae. Although the mean age of the cases with chondromalacia was higher than the cases without chondromalacia, there was no significant difference between male and female individuals.
\end{abstract}

Keywords: Chondromalacia; patellar volume; knee pain.

Cite this article as: Sirik M, Uludag A. Assessment of the relationship between patellar volume and chondromalacia patellae using knee magnetic resonance imaging. North Clin Istanb 2020;7(3):280-283.

$\mathrm{C}$ hondromalacia patella is a condition that may involve a wide range of areas from a small fissure in the hyaline cartilage on the surface of the joints to a total loss of cartilage in the subchondral area and results in anterior and anterolateral knee pain [1-4]. Chondromalacia patellae can be seen at both young and advanced ages. In the former, it may develop due to fragmentation of carti- lage in joints by instantaneous and torsional forces during high-energy sports, such as cycling, football, jogging, skiing, and gymnastics, while in the latter group. Chondromalacia patellae usually occurs chronically as a result of vascular traumas or micro-traumas [5]. Tibiofemoral and patellofemoral joint incongruence are influential in the development of chondromalacia patellae. The direction and

Our study was presented as 'verbal presentation' in annual meeting of the Turkish Magnetic Resonance Association, 2018.

Received: November 05, 2018 Accepted: September 16, 2019 Online: October 10, 2019

Correspondence: Dr. Mehmet SIRIK. Adiyaman Universitesi Tip Fakultesi Egitim ve Arastirma Hastanesi, Radyoloji Klinigi, Adiyaman Turkey.

Tel: +90 4162161015 - 2230 e-mail: dr.mmtsrk@gmail.com

(c) Copyright 2020 by Istanbul Provincial Directorate of Health - Available online at www.northclinist.com 
type of force, patellar height, the shape of the patellar and trochlear groove, patellar tilt, and the distance between tibial tuberosity and the trochlear groove [6-10] have an effect on the complex structure of the patellofemoral joint. However, the relationship between patellar volume and development of chondromalacia patellae has not yet been clarified. This study investigated the correlation between patellar volume and chondromalacia patellae.

\section{MATERIALS AND METHODS}

Our research was approved by the local ethics committee. A total of 162 patients that underwent knee magnetic resonance (MR) due to knee pain at our clinic between January 1, 2017, and May 31, 2017, were included in this study. According to the MR examination, 111 patients had chondromalacia patellae, and 51 individuals had normal findings. The MR images were obtained using the $1.5 \mathrm{~T}$ system (Philips, Achieva, the Netherlands). The patellar volume of all cases was analyzed using the PD SPAIR sequence [Repetition Time (TR) 3034 ms, Echo Time (TE) $30 \mathrm{~ms}$, slice thickness $3.5 \mathrm{~mm}$, and Gap $0.3 \mathrm{~mm}$ ) using semi-automated software on the workstation (Fig. 1 ). The cases of chondromalacia were graded according to the Outerbridge classification from stage 1 to stage 4 .

\section{Statistical Analysis}

In the statistical analysis, the categorical values of the cases were expressed in numbers and percentages. Numerical data without normal distribution were obtained as minimum, maximum and median values. The distribution of numerical data was evaluated using the Shapiro Wilk test. Pearson's Chi-square test was used to compare categorical data and the Mann-Whitney U test was used to compare numerical data between the two groups. Spearman's correlation analysis was undertaken to analyze the correlation of the stage of chondromalacia with patellar volume and cartilage thickness. SPSS 21.0 software (IBM Corp. New York, USA) was used for statistical analysis. The relationship between patellar volume and chondromalacia presence and grade, cartilage thickness, age, and sex was statistically analyzed.

\section{RESULTS}

A total of 162 cases were included in this study, of which 67 (41.4\%) were male, and 95 (58.6\%) were female. Chondromalacia patella was found in $111(68.5 \%)$ cases. Of the chondromalacia patellae cases, 23 (20.7\%) were

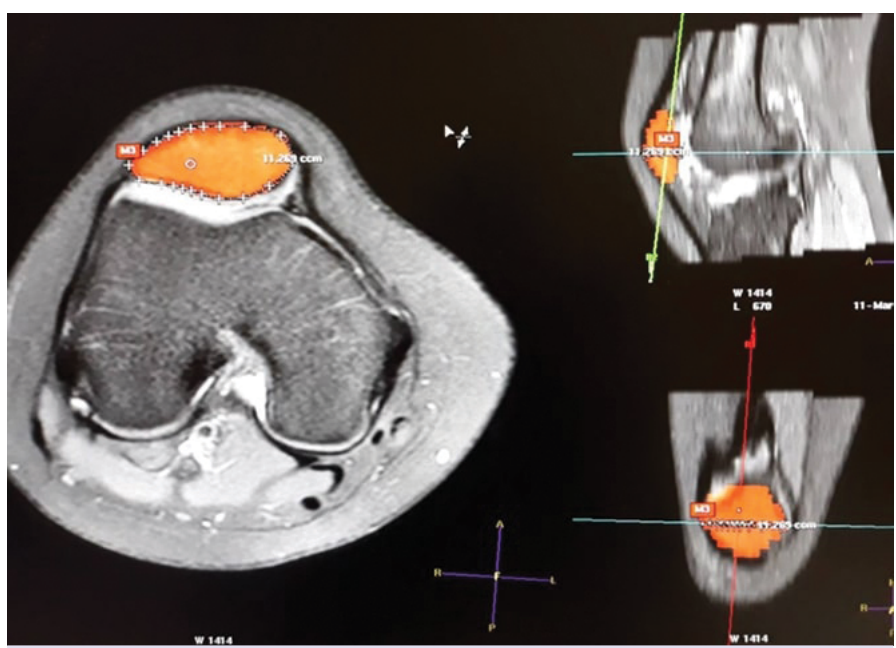

FIGURE 1. Calculation of the patellar volumes of cases from the PD SPAIR sequence (Repetition Time 3034 ms, Echo Time $30 \mathrm{~ms}$, slice thickness $3.5 \mathrm{~mm}$, Gap $0.3 \mathrm{~mm}$ ) using semi-automated software on the workstation.

grade I, $52(46.8 \%)$ were grade II, $32(28.8 \%)$ were grade III, and $4(3.6 \%)$ were grade IV. None of the numerical data showed the normal distribution in the Shapiro Wilk test; thus, nonparametric tests were used in the statistical analysis. The minimum, maximum and median ages of the 162 cases were 18,74, and 44, respectively. Patellar volume was measured as a minimum of $12.24 \mathrm{~cm}^{3}$, a maximum of $39.44 \mathrm{~cm}^{3}$, and a median $21.4 \mathrm{~cm}^{3}$. The thickness of cartilage measured from the medial facet was a minimum of $1.6 \mathrm{~mm}$, a maximum of $5.9 \mathrm{~mm}$ and a median $3.2 \mathrm{~mm}$. The thickness of cartilage measured from the lateral facet was a minimum of $1.6 \mathrm{~mm}$, a maximum of $5.9 \mathrm{~mm}$ and a median $3.2 \mathrm{~mm}$. Chondromalacia patellae was present in $45(67.16 \%)$ male cases $(67.16 \%)$ and 66 (69.47\%) female cases $(n=95)$ with no statistically significant difference according to sex in Pearson's Chi-square test $(p=0.755)$. Age also did not differ significantly between men and women. Patellar volume and medial and lateral facet cartilage thickness were statistically higher in males than in females (Table 1). The age of the patients with chondromalacia was statistically significantly higher than that of individuals without this condition. Furthermore, in cases with chondromalacia, patellar volume was higher, the thickness of the cartilage in the medial fascia was lower, and the difference was statistically significant for both. There was no statistically significant difference in the cartilage thickness measured from the lateral facet. In chondromalacia patients, a statistically significant, weak, and positive correlation was found between chondromalacia grade and patellar volume $(p=0.031$, 
TABLE 1. Numerical data on age, patellar volume and cartilage thickness by sex*

\begin{tabular}{lccc} 
& $\begin{array}{c}\text { Male } \\
\text { Median }\end{array}$ & $\begin{array}{c}\text { Female } \\
\text { Median }\end{array}$ & $\mathrm{p}$ \\
\hline $\begin{array}{l}\text { Age } \\
\text { Patellar volume }\left(\mathrm{cm}^{3}\right)\end{array}$ & 23.41 & 46 & 0.292 \\
$\begin{array}{l}\text { Cartilage thickness at } \\
\text { the medial facet }(\mathrm{mm})\end{array}$ & 3.3 & 20.12 & $<0.0001$ \\
$\begin{array}{l}\text { Cartilage thickness at } \\
\text { the lateral facet }(\mathrm{mm})\end{array}$ & 3.5 & 3.1 & 0.017 \\
\hline
\end{tabular}

*Mann-Whitney-U test.

TABLE 2. Numerical data on age, patellar volume, and cartilage thickness according to the presence of chondromalacia patellae*

\begin{tabular}{lccc} 
& $\begin{array}{c}\text { Chondromalacia } \\
\text { patellae present } \\
\text { Median }\end{array}$ & $\begin{array}{c}\text { Chondromalacia } \\
\text { patellae absent } \\
\text { Median }\end{array}$ & $\mathrm{p}$ \\
& 49 & 32 & $<0.0001$ \\
\hline Age & 21.84 & 19.73 & 0.026 \\
$\begin{array}{l}\text { Patella volume }\left(\mathrm{cm}^{3}\right) \\
\text { Cartilage thickness at } \\
\text { the medial facet }(\mathrm{mm})\end{array}$ & 3 & 3.5 & 0.001 \\
$\begin{array}{l}\text { Cartilage thickness at } \\
\text { the lateral facet }(\mathrm{mm})\end{array}$ & 3.3 & 3.1 & 0.353 \\
\hline
\end{tabular}

*Mann-Whitney-U test

$r=0.204)$; however, there was no statistically significant correlation between chondromalacia grade and the medial and lateral facet cartilage thickness $(p=0.446, r=$ 0.073 and $p=0.444, r=-0.073$, respectively) (Table 2 ).

\section{DISCUSSION}

Patellar cartilage damage may develop acutely as a result of direct trauma, but may also occur chronically due to microtraumas. There is limited research investigating whether micro-traumas may cause chondromalacia patellae in predisposed cases, and some studies have been undertaken on tibiofemoral and patellofemoral joints; however, they mostly focused on the patellofemoral joint, which has a more complex structure. The effects of alignment disorders related to patellar height, patellar and trochlear groove, patellar tilt, and the distance between tibial tuberosity and trochlear groove have been investigated [7-10]. However, to our knowledge, no assessment has been performed on patellar volume, a structural characteristic of individuals. Patellar cartilage defects are closely related to the geometry of the patellofemoral joint. Patellar height, patellar lateral facet width, patellar lateral facet ratio, sulcus depth, lateral patellar displacement, patellar epicondylar congruence angle, and abnormal length of the lateral condyle have been associated with chondromalacia patellae $[6,10,11]$. It has been reported that frequent recurrent dislocations, subluxations, and especially severe patellar femoral cartilage defects in the presence of patella alta also increase the presence of chondromalacia patellae $[6,12-17]$. A flat and shallow femoral trochlea with less sulcus depth that arises from an increased sulcus angle defined by the angle between the lateral condyle and the medial condyle on the transverse plane used in the identification of the trochlear morphology may result in disproportionate load distribution across the patellofemoral joint during knee movement, increasing the pressure on this joint and leading to the development of chondromalacia $[8,10,18,19]$. Stabilization of the patellofemoral joint by bone and cartilage is weakened in the presence of trochlear dysplasia, which leads to patellofemoral disorder, instability, dislocation, and, ultimately an increased risk of cartilage damage $[10,20]$. Damage or weakness of ligament and joint capsules plays an important role in joint stability, which is also known to cause joint degeneration. Joint subluxations due to the disruption of the ligament and capsule functions cause instability, resulting in incongruence in the surfaces of joints, e.g., trochlear disorder, preventing the normal distribution of weight and stress and increasing the risk of joint cartilage injury. In all important studies, it has been shown that a high body weight and body mass index (BMI) have detrimental effects on patellar cartilage. It has been found that increased fat thickness of subcutaneous knee circumference, which is an indicator of obesity in middle-aged adults, especially women, is positively correlated with the presence and severity of patellar cartilage defects in MR imaging [21, 22].

In this study, patellar volume was higher in patients with chondromalacia patellae. The mean patellar medial facet cartilage thickness was lower in the patients with chondromalacia. As expected, the risk of chondromalacia increased with age. Although it was slightly higher in females, no significant difference was found between men and women with chondromalacia patellae in our study. Furthermore, there was a significant but weak relationship between patellar volume and chondromalacia grade. 
The limitations of this study include the lack of an assessment of the relationship between patellar volume and BMI of cases and data loss that arises from the routine MR section thickness, both due to the retrospective design. Further studies can be planned with thin-section MR imaging to evaluate chondromalacia cases according to BMI and calculate the optimal patellar volume. In this study, the difference of age was statistically significant between the study and control group, which may cause bias due to possible effects of age on other parameters. Besides, a statistically significant difference in patellar volume between males and females may cause bias, as well. Thus, further studies with a more homogeneous population in study and control groups are needed.

In conclusion, our study demonstrated a significant correlation between chondromalacia patellae and patellar volume, in which as the patellar volume increased, the chondromalacia risk increased and cartilage thickness at the medial facet of the patella decreased at a further level compared to the lateral measurement. There was also a significant but weak relationship between patellar volume and grade of chondromalacia patellae. The mean age was higher in the cases with chondromalacia than the cases without chondromalacia, but chondromalacia frequency did not significantly differ between men and women.

Ethics Committee Approval: Adiyaman University Non-Interventional Research Ethics Committee granted approval for this study (date: 26.06.2018, number: 2018/5-26).

Conflict of Interest: No conflict of interest was declared by the authors.

Financial Disclosure: The authors declared that this study has received no financial support.

Authorship Contributions: Concept - MS, AU; Design - MS, AU; Supervision - MS, AU; Materials - MS, AU; Data collection and/or processing - MS, AU; Analysis and/or interpretation - MS, AU; Writing - MS, AU; Critical review - MS, AU.

\section{REFERENCES}

1. Gagliardi JA, Chung EM, Chandnani VP, Kesling KL, Christensen KP, Null RN, et al. Detection and staging of chondromalacia patellae: relative efficacies of conventional MR imaging, MR arthrography, and CT arthrography. AJR Am J Roentgenol 1994;163:629-36. [CrossRef]

2. McCauley TR, Kier R, Lynch KJ, Jokl P. Chondromalacia patellae: diagnosis with MR imaging. AJR Am J Roentgenol 1992;158:101-5.

3. Pihlajamäki HK, Kuikka PI, Leppänen VV, Kiuru MJ, Mattila VM. Reliability of clinical findings and magnetic resonance imaging for the diagnosis of chondromalacia patellae. J Bone Joint Surg Am 2010;92:927-34. [CrossRef]

4. Tung GA, Davis LM. The role of magnetic resonance imaging in the evaluation of the soft tissue mass. Crit Rev Diagn Imaging 1993;34:239-308.

5. Wheaton MT, Jensen N. The ligament injury connection to osteoarthritis. Journal of Prolotherapy 2010;2:294-304.

6. Mehl J, Feucht MJ, Bode G, Dovi-Akue D, Südkamp NP, Niemeyer P. Association between patellar cartilage defects and patellofemoral geometry: a matched-pair MRI comparison of patients with and without isolated patellar cartilage defects. Knee Surg Sports Traumatol Arthrosc 2016;24:838-46. [CrossRef]

7. Ali SA, Helmer R, Terk MR. Analysis of the patellofemoral region on MRI: association of abnormal trochlear morphology with severe cartilage defects. AJR Am J Roentgenol 2010;194:721-7. [CrossRef]

8. Kalichman L, Zhang Y, Niu J, Goggins J, Gale D, Felson DT, et al. The association between patellar alignment and patellofemoral joint osteoarthritis features--an MRI study. Rheumatology (Oxford) 207;46:1303-8. [CrossRef]

9. Tsavalas N, Katonis P, Karantanas AH. Knee joint anterior malalignment and patellofemoral osteoarthritis: an MRI study. Eur Radiol 2012;22:418-28. [CrossRef]

10. Yang B, Tan H, Yang L, Dai G, Guo B. Correlating anatomy and congruence of the patellofemoral joint with cartilage lesions. Orthopedics 2009;32:20. [CrossRef]

11. Biedert RM, Netzer P, Gal I, Sigg A, Tscholl PM. The lateral condyle index: a new index for assessing the length of the lateral articular trochlea as predisposing factor for patellar instability. Int Orthop 2011;35:1327-31. [CrossRef]

12. Hughston JC. Subluxation of the patella. J Bone Joint Surg Am 1968;50:1003-26. [CrossRef]

13. Insall J, Goldberg V, Salvati E. Recurrent dislocation and the high-riding patella. Clin Orthop Relat Res 1972;88:67-9. [CrossRef]

14. Lancourt JE, Cristini JA. Patella alta and patella infera. Their etiological role in patellar dislocation, chondromalacia, and apophysitis of the tibial tubercle. The Journal of Bone and Joint surgery. American Volume 1975;57:1112-5. [CrossRef]

15. Marks KE, Bentley G. Patella alta and chondromalacia. J Bone Joint Surg Br 1978;60:71-3. [CrossRef]

16. Rünow A. The dislocating patella. Etiology and prognosis in relation to generalized joint laxity and anatomy of the patellar articulation. Acta Orthop Scand Suppl 1983;201:1-53. [CrossRef]

17. Ali SA, Helmer R, Terk MR. Patella alta: lack of correlation between patellotrochlear cartilage congruence and commonly used patellar height ratios. AJR Am J Roentgenol 2009;193:1361-6. [CrossRef]

18. Stefanik JJ, Roemer FW, Zumwalt AC, Zhu Y, Gross KD, Lynch JA, et al. Association between measures of trochlear morphology and structural features of patellofemoral joint osteoarthritis on MRI: the MOST study. J Orthop Res 2012;30:1-8. [CrossRef]

19. Duran S, Cavusoglu M, Kocadal O, Sakman B. Association between trochlear morphology and chondromalacia patella: an MRI study. Clin Imaging 2017;41:7-10. [CrossRef]

20. Schöttle PB, Fucentese SF, Pfirrmann C, Bereiter H, Romero J. Trochleaplasty for patellar instability due to trochlear dysplasia: A minimum 2-year clinical and radiological follow-up of 19 knees. Acta Orthop 2005;76:693-8. [CrossRef]

21. Hussain SM, Tan MC, Stathakopoulos K, Cicuttini FM, Wang Y, Chou L, et al. How Are Obesity and Body Composition Related to Patellar Cartilage? A Systematic Review. J Rheumatol 2017;44:1071-82. [CrossRef]

22. Kok HK, Donnellan J, Ryan D, Torreggiani WC. Correlation between subcutaneous knee fat thickness and chondromalacia patellae on magnetic resonance imaging of the knee. Can Assoc Radiol J 2013;64:182-6. 